\title{
Will the Real "Natural Trading Partner" Please Stand Up?
}

\author{
Maurice Schiff* \\ World Bank
}

\begin{abstract}
Adherents to the "natural trading partner" hypothesis argue that forming a PTA is more likely to raise welfare if member countries already trade disproportionately with each other. Opponents of the hypothesis claim that the opposite is true: welfare is likely to be higher if member countries trade less with each other. This paper shows that neither analysis is correct and that the "natural trading partner" hypothesis can be rescued if it is redefined in terms of complementarity or substitutability rather than in terms of volume of trade.
\end{abstract}

- JEL Classifications: F02, F13, F15

- Key Words: Regional Integration, Partner Relations with the Rest of the World, Choice of Partner

\section{Introduction}

The "natural trading partner" hypothesis has recently become popular in the regional integration literature. Two versions of the hypothesis exist, referring either to the volume of trade between potential partners of a preferentional trading arrangement (PTA) or to the distance and transport costs between them. Authors who adhere to the hypothesis argue that integration with "natural trading partners" is likely to raise welfare because the likelihood and extent of trade diversion is minimized when the volume of trade between prospective partners is large. Others

\footnotetext{
*Corresponding address: Development Reserach Group World Bank Mailstop No. MC3-303. 1818 H. Streer NW Washington D.C. 20433 USA. Email: mschiff@ worldbank.org, Tel. +1-202-473-7963, Fax. +1-202-522-1159 (C)2001-Center for International Economics, Sejong Institution, All Rights Reserved.
} 
argue the opposite. And though it is true that the "natural trading partner" hypothesis does not hold in general, the studies aiming to refute it have some analytical problems of their own which have so far been ignored in the literature.

This paper shows that the analysis requires a more careful examination of the link between the partner country and the rest of the world, and that such an examination leads to different results. ${ }^{1}$ It is shown that commercial opportunities exist whose exploitation has not been fully examined in the traditional analysis of the "natural trading partner" hypothesis. One of the implications of the analysis presented here is that an alternative definition of "natural trading partner" exists under which the hypothesis is likely to hold.

The paper is organized as follows. Section 2 presents the "natural trading partner" hypothesis as found in the literature and Section 3 shows the analysis aimed at refuting it. Section 4 lists the main implications of that analysis. Section 5 points out its limitations and presents a new analysis. Section 6 concludes and provides new policy recommendations. The "natural trading partner" hypothesis is rescued once appropriate changes in the definition are made. ${ }^{2}$

\section{The 'Natural Trading Partner” Hypothesis}

A number of studies claim that if two countries or regions are "natural trading partners", they are more likely to gain from a preferential trade agreement (PTA) between them. The claim based on the version of the hypothesis referring to the volume of trade apparently originates with Lipsey (1960). He argues in his famous survey that " $\ldots$ a customs union is more likely to raise welfare the higher is the proportion of trade with the country's union partner and the lower the proportion with the outside world." In a similar vein, Summers (1991) states: "Are trading blocs likely to divert large amounts of trade? In answering this question, the issue of natural trading blocs is crucial because to the extent that blocs are created between countries that already trade disproportionately, the risk of large amounts of trade diversion is reduced". Also, Wonnacott and Lutz (1989) state that if the prospective members are already major trading partners, integration "... will be

\footnotetext{
'The link between partner country and rest of the world has been examined in $3 \times 3$ models, including Riezman (1979) and Lloyd (1982). Bagwell and Staiger (1993a, b) and Bond and Syropoulos (1996) endogenize trade agreements and show that maintaining free trade is harder in a bloc-ridden world. None of these papers examines the "natural trading partner" hypothesis.

${ }^{2}$ The term "traditional" for this type of analysis is also found in the title of Panagariya (1999).
} 
reinforcing natural trading patterns, not artificially diverting them" (p. 69). The same point is made in a 1995 communication from the EU Commission to the EU Council entitled "Free Trade Areas: An Appraisal" which states that PTAs between "natural trading partners" are less likely to generate trade diversion effects.

What about the version of the hypothesis associated with location and transport costs? Wonnacott and Lutz (1989) argue that, ceteris paribus, since proximity between PTA members increases trade between them (due to lower transport costs), it reduces the extent of trade diversion and increases the benefits of PTAs, a point also made by Deardorff and Stern (1994). Krugman (1993, pp. 63, 64) argues that due to transportation and communication costs, there is a strong tendency for countries to trade with their neighbors. And if free trade agreements (FTAs) are formed with neighbors, the gains from freeing intra-regional trade will be larger and the losses of reducing interregional trade will be smaller than if these costs are ignored. Similarly, Krugman (1991) states that "If a disproportionate share of world trade would take place within trading blocs even in the absence of any preferential trading arrangement, then the gains from trade creation within blocs are likely to outweigh any possible losses from external trade diversion."

Though being the most popular, the definition of "natural trading partners" based on the volume of trade criterion is more difficult to justify. The volume of trade does not necessarily provide an objective measure of the extent to which trading partners are "natural". The reason is that the volume of trade is itself affected by trade policy. Ideally, we would like to have a "natural trading partners" criterion that is independent of trade policy. Such a criterion is proposed in this paper.

Note also that if losses to a PTA depend on the extent of trade diversion, this is not necessarily true for individual members who may lose or gain from the redistribution of tariff revenues within the PTA even in the absence of trade diversion. This is the heart of the challenge of the traditional analysis to the "natural trading partner" hypothesis.

\section{Traditional Analysis}

An early non-technical critique of the "natural trading partner" hypothesis is Bhagwati (1993) who details the shortcomings of the hypothesis as expounded by Krugman and Summers. More formal analyses include Bhagwati and Panagariya (1996), Michaely (1998), Panagariya (1996, 1997, 1999) and Schiff (1997). Most 
studies use a partial equilibrium approach, while Michaely (1998) uses a diagrammatic general equilibrium framework to obtain the same results. As stated in Bhagwati and Panagariya (p. 35), Michaely (p. 74) and Schiff (p. 363), the studies of PTAs focus on FTAs. This paper examines customs unions (CUs) as well. The standard analysis typically assumes three countries, the home country A, the partner country $\mathrm{B}$ and the rest of the world $\mathrm{C}$, as well as perfect competition and product homogeneity. ${ }^{3}$ In the pre-PTA situation, A imposes an MFN tariff on imports of B and C. The same assumptions are made in our analysis in Section 4.

Under homogeneity, a necessary condition for small countries to gain from forming a PTA is that they stop trading with the rest of the world (Wonnacott and Wonnacott 1981). A welfare gain can be obtained without having to assume such corner solutions if one assumes product differentiation, for instance, following Armington by country of origin. Though this assumption provides additional flexibility, it does so at a cost. With product differentiation, each country has monopoly power in the good it produces and free trade is no longer optimal for the country or region. Homogeneity is assumed in the remainder of the paper.

\section{A. Small in All Markets}

The first case considered is the Vinerian constant cost model, where the home country A is small relative to both $B$ and $C$ and takes their prices as given. As is well known, if $B$ has lower costs than $C, B$ is the only supplier to $A$ in the pre-PTA situation and a PTA with $B$ is equivalent to unilateral liberalization, with A benefiting from the traditional gains from trade. This is a case of pure trade creation. Given $B$ 's constant cost, its welfare is not affected, and the welfare gain of the PTA as a whole equals that of $A$. Since $C$ 's welfare is also unaffected, the worlds welfare gain equals that of $A$ as well.

If $B$ has higher costs than $C$, then $C$ is the only supplier to $A$ in the pre-PTA situation. With a PTA between $A$ and $B$, imports from $B$ displace imports from $C$ in A's market (as long as $B$ 's cost is not higher than $C$ 's inclusive of A's tariff). $A$ 's terms of trade deteriorate and it loses a (large) rectangular area from trade

\footnotetext{
${ }^{3}$ Bhagwati and Panagariya (1996) and Panagariya (1997) also examine the case of heterogeneous products. The latter one is based on the Meade model, where each of the three countries produces one good and imports the other two, with similar results about the impact of the volume of trade on the effect of a PTA. The paper concludes (p. 487): "It may be asked whether the results remain valid in models of product differentiation and economies of scale. The broad answer is in the affirmative." In Meades model, the partner exports to the home country and to the rest of the world. This paper examines, under homogeneity, the case of the partner exporting to the home country and either exporting to the rest of the world or importing from it.
} 
Figure 1.

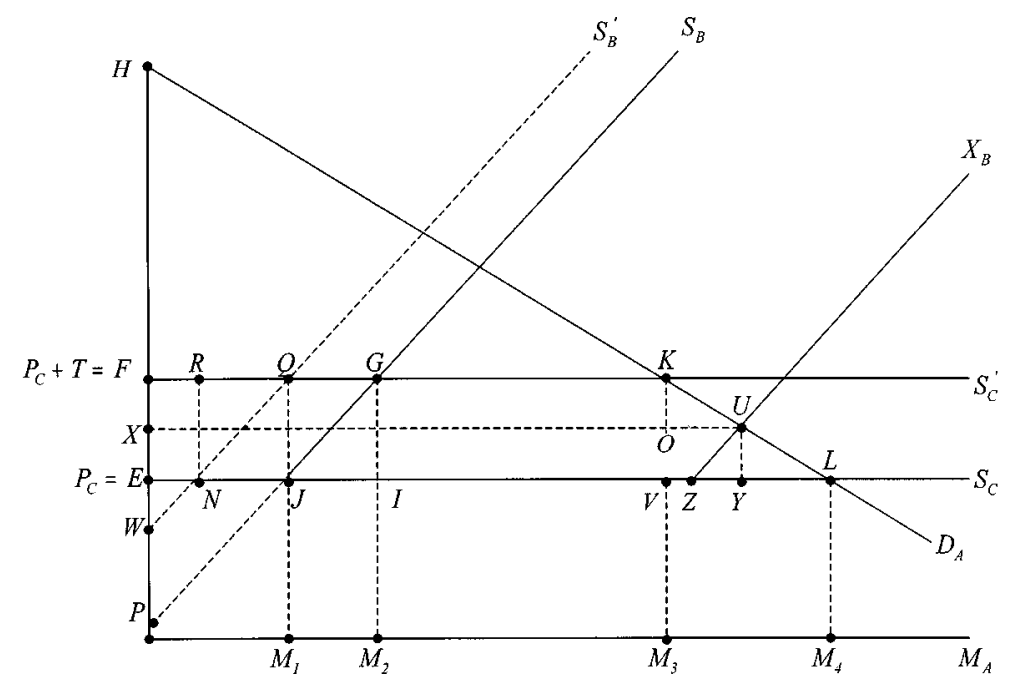

diversion whose size depends on the cost difference between $B$ and $C$ and on the initial level of imports. A also gains a (typically smaller) triangular area because the lower market price results in some trade creation. The net effect is (presumably) negative. The same holds for the PTA's and the world's welfare.

We now examine the case where $B$ has an upward-sloping supply curve of exports to $A$, denoted by $S_{B}$ in Figure 1 . $C$ 's supply to $A$ is horizontal as before. Thus, $A$ is large in $B$ 's market but is small in the world market $C$. We examine first the case where A forms a PTA with $B$ and then the alternative case where $A$ forms a PTA with $C$.

\section{B. Large (Small) in Partner's (Outside) Market}

Before the PTA is formed, $A$ applies a non-discriminatory (MFN) specific tariff $T$, and faces the supply curves $S_{C}^{\prime}$ from $C$ and $S_{B}^{\prime}$ from $B$ (see Figure 1). $A$ imports $M_{1}$ from $B$ and $M_{3} M_{1}$ from $C$. The price in $A, P_{A}$, is: $P_{A}=P_{C}+T$. $A$ 's welfare is the difference HKVE between the value of imports and the spending on them. This equals the consumer surplus HKF+ tariff revenues KVEF. $B$ 's welfare is FQW= EJP. With a PTA between $A$ and $B, S_{B}^{\prime}$ increases to $S_{B}$ while $S_{C}^{\prime}$ is unchanged. $A$ 's imports from $B$ increase to $M_{2}$ and those from $C$ fall to $M_{3} M_{2}$. Since $A$ no longer charges the tariff $T$ on imports from $B$, it loses rectangle EFGI. And this loss increases with the volume of trade. On the other hand, $B$ 's producer surplus increases by EFGJ. And $B$ 's gain increases with the volume of trade as well. Note 
that EFGJ $<$ EFGI. Thus, the loss to $A$ is larger than the gain to $B$ and the PTA as a whole loses GIJ. The reason is trade diversion: $M_{1} M_{2}$ was previously imported from $C$ and is now imported from $B$ at a higher cost (along JG rather than JI). And there is no trade creation: the marginal unit is still imported from $C$ at the same cost $P_{A}=P_{C}+T$ so that total imports remain unchanged.

\section{Small (Large) in Partner's (Outside) Market.}

Finally, with a PTA between $A$ and $C, A$ faces $S_{C}$ from $C$ rather than $S_{C}$. Then, $P_{A}=P_{C}$ and $A$ gains area KLV+EFRN (tariff revenue collected on imports from outsider $B$ ). Welfare of $C$ is unchanged so that the PTA as a whole ( $A$ plus $C$ ) gains $\mathrm{KLV}+\mathrm{EFRN}$. And $B$ loses EFQN. Note that here too, the larger the imports from the partner (country $C$ ), the smaller the tariff revenues obtained from outsider $B$ and the smaller $A$ 's gains and the PTAs gains. Though $A$ and the PTA gain in this case, the gains fall as A's imports from the partner increase. The impact on world welfare is $\mathrm{KLV}+\mathrm{EFRN}-\mathrm{EFQN}=\mathrm{KLV}$ (trade creation) $-\mathrm{RQN}$ (trade diversion), and may be positive or negative.

This case is examined in detail in Bhagwati and Panagariya (1996, pp. 46-47) and in Schiff (1997, pp. 366-367). These studies have several shortcomings, one of which is examined here (and the others in Section 5). They assume that country $B$ continues to export to $A$ after $A$ forms a PTA with $C$. Since the domestic price in $A$ falls to $P_{C}, B$ obtains $P_{C}-T$ in $A$ 's market but obtains $P_{C}$ in $C$ 's market. Thus, $B$ will switch its exports from $A$ to $C$, and the above results do not hold. ${ }^{4}$ In fact, $A$ gains KLV but not EFRN, B's welfare is unchanged, the world gains KLV, and $A$ 's and the PTA's gains are invariant with respect to A's pre-PTA imports from the partner.

\section{Main Implications from the Traditional Analysis}

Four main implications that have been drawn from the traditional analysis are:

i) The losses to $A$ from a PTA with $B$ do not depend only on the degree of trade diversion $M_{1} M_{2}$. They are also affected by the revenue loss (or worsening of the terms of trade) on the initial import level $M_{1}$. In fact, $A$ loses tariff revenue even in the total absence of trade diversion, with $S_{B}$ vertical at level $M_{1}$.

ii) The loss to $A$ is proportional to the post-PTA imports from $B$. Thus, the

\footnotetext{
${ }^{4}$ The results do hold if $\mathrm{C}$ imposes an import tariff larger than or equal to T. Wonnacott and Wonnacott (1981) assume such a tariff in their analysis of regional integration.
} 
greater the imports from $B$, the greater $A$ 's losses. This is the basis for the challenge to the "natural trading partner" hypothesis. Of course, this only deals with the import side. Clearly, the gains to $A$ rise with the volume of $A$ 's exports to $B$. There are thus two opposing effects and the impact of the volume of trade on the effect of a PTA on A's welfare is ambiguous a priori.

Bhagwati and Panagariya (1996, pp. 47-48) argue that in the case of NorthSouth PTAs (e.g., NAFTA), since the North typically has lower trade barriers than the South, the South gives more to the North than it receives from it, and thus loses from the PTA. According to this argument, ceteris paribus, the South (e.g., Mexico) is better off forming a PTA with a distant Northern region (e.g., the EU or Japan) than with one nearby (e.g., the US) because the welfare loss for the South is smaller if trade with the partner country is lower. In general, a country gains more from a PTA if its tariffs are low while those of the partner are high, and if it imports little from the partner and exports a lot to it (Schiff 1997).

iii) A PTA between two small price-taking countries must result in a welfare loss for the PTA as a whole as long as trade with the rest of the world $C$ continues to take place. There is no trade creation in this case and the only effect is trade diversion.

iv) We have seen that for a PTA made up of countries $A$ and $B$, the loss for the PTA as a whole is JIG. As long as the slope of $S_{B}$ is constant, this loss is independent of its location. Thus, a higher volume of trade does not reduce the PTA's loss from trade diversion. Assuming that the elasticity rather than the slope of B's supply curve is constant, the extent of trade diversion rises with the volume of trade. Then, the losses to the PTA increase with the volume of trade (Schiff 1997). This is precisely the opposite of the prediction from the "natural trading partner" hypothesis.

Implications i), ii) and iv) also hold when $A$ is large in both $B$ and $C$, i.e., when both $S_{B}$ and $S_{C}$ are upward-sloping (Schiff 1997).

\section{The Reality of Commercial Opportunity}

The standard analysis carefully examines the trade relationship between $A$ and $B$ and between $A$ and $C$. The same cannot be said of the trade relationship between $B$ and $C$. This lacuna has a fundamental impact on the results. An alternative analysis is provided in this section. ${ }^{5}$

\footnotetext{
${ }^{5}$ We maintain the assumption of the traditional analysis that tariff rates are given exogenously. For an analysis of endogenous determination of tariff rates, see Grossman and Helpman (1994, 1995), Cadot, de Melo, Olarreaga (1996) and Olarreaga and Soloaga (1998).
} 


\section{A. Small in All Markets.}

We start with the constant cost model where $A$ takes prices in both $B$ and $C$ as given. A question that arises is how the two prices of $B$ and $C$ can coexist. If, say, $P_{C}<P_{B}, C$ can sell to $B$. If $C$ is large relative to $B$, the equilibrium price is $P_{C}$; if $B$ is large relative to $C$, the equilibrium price is $P_{B}$; and otherwise it is between $P_{B}$ and $P_{C}$. The main point is that $A$ will face a single price on the world market and is then indifferent whether it forms a PTA with $B$ or $C$. Such a PTA is equivalent to unilateral liberalization.

To maintain the standard results, one needs to assume that there is no such arbitrage between countries $B$ and $C$. This is obtained if the country with the higher cost applies a tariff that is larger than or equal to the difference in costs between $B$ and $C$. In this particular case, the correction is simple and all the standard results continue to hold. This is not the case below.

\section{B. Large (Small) in Partners (Outside) Market.}

Assume now, as done in Section 2, that A is small in world market $C$ but is large in $B$ 's market. $B$ is small in $C$ 's market as well. We now need to specify the trade relationship between $B$ and $C$. The good is either exported from $B$ to $C$ or imported by $B$ from $C$. We assume that $C$ exports or imports at price $P_{C}$. Define $P^{*}{ }_{C} \equiv P_{C^{-}}$ $T_{C}$. The results of the analysis that follows also hold in the case where $C$ charges a tariff $T_{C}$ on its imports if $P_{C}$ is replaced by $P^{*}{ }_{C}$ as $C$ 's import price.

\section{$B$ exports to $C$.}

There are three destinations for $B$ 's output: $A$ 's market, $C$ 's market, and $B$ 's domestic consumers. What is the nature of $B$ 's export supply curve to $A$ ? Since $B$ can export to $C$ at price $P_{C}$, its export supply to $A$ is zero for any price $P_{A}<P_{C}$. At $P_{A}=P_{C}, B$ is indifferent between exporting to $C$ or to $A$. For $P_{A}>P_{C}, B$ sells all its exports in $A$ and none in $C$. There are thus three segments to $B$ 's export supply curve. In Figure 1, the first segment starts at the origin and is equal to zero up to point $E$. The second segment is horizontal at price $P_{C}$ from point $E$ to (say) point $Z$. The third segment is upward sloping, from (say) point $Z$ to point $U$ and continuing up as shown by the curve $X_{B}$. Thus, $B$ 's export supply curve is not $S_{B}$ in Figure 1.

As long as $B$ exports to $C$, whether $A$ and $B$ form a $C U$ or a FTA has no impact on the analysis since $B$ 's tariff does not apply. Before $B$ forms a PTA with $A, B$ 
receives the world price $P_{C}$ on its exports to $C$ and on its exports to $A$ as well (the price in $\mathrm{A}$ is $P_{A}=P_{C}+T$ and $B$ pays a tariff $T$ on exports to $A$ ). $B$ is therefore indifferent between exporting to $C$ or to $A$. Consequently, the volume of exports from $B$ to $A$ is indeterminate (and not volume $M_{1}$ in Figure 1 as obtained in the standard analysis). This indeterminacy is of no consequence for the analysis of the welfare impact of the PTA.

Assume now that $A$ and $B$ form a PTA. The standard analysis assumes a move along $B$ 's export supply curve $S_{B}$ from point $J$ to point $G$ in Figure 1, with an increase in $B$ 's exports to $A$ from $M_{1}$ to $M_{2}$. In fact, since $B$ is exporting to $C$ at price $\mathrm{P}_{\mathrm{C}}$, and can now obtain a price $P_{C}+T$ in $A$ 's market, $B$ 's exporters simply switch exports from $C$ 's market to $A$ 's market. $B$ 's export supply curve to $A$ following integration is thus identical to $S_{C}$, either to the point where all exports are sold in $A$ 's market and none in $C$ 's market, or exports equal $M_{4}$.

From the viewpoint of $A$ and $B$ 's welfare, where the export supply curve starts sloping upwards is crucial. First, if that happens at or beyond volume $M_{4}$ (point $L$ ), A gains KLV as in the case of unilateral liberalization, $B$ 's welfare is unchanged, and the PTA gains KLV. Note that the likelihood of reaching that point is higher under our analysis than under the standard one given that $B$ can switch exports from $C$ to $A$.

Second, assume $B$ 's export supply curve intersects $A$ 's import demand curve between $K$ and $L$ (as shown by the curve $X_{B}$ in Figure 1). Then, $B$ gains from the higher export price while the impact on $A$ is ambiguous: it loses from a worsening of its terms of trade but gains from the lower price and increased trade (trade creation). For instance, if the export supply curve $X_{B}$ intersects the import demand curve in point $\mathrm{U}$ in Figure 1, $A$ 's gain is FKUX (increase in consumer surplus) and the loss is EFKV (loss in tariff revenue), or a net gain of KUO and a net loss of EXOV. The net loss EXOV is likely to be larger than the net gain KUO because the net loss applies to the entire pre-PTA volume of imports while the net gain only applies to the increase in imports. However, whether $A$ gains or loses also depends on where $U$ is located on the segment KL. If $\mathrm{U}$ is close to $L, A$ is likely to gain; otherwise it will lose. $B$ gains EXUZ.

Third, assume the export supply curve $X_{B}$ intersects the horizontal section FK to the left of K. Then, A's domestic price continues to be $P_{C}+T$. A loses tariff revenue to $B$ (i.e., $A$ 's terms of trade worsen). Such an outcome is less likely than in the standard analysis because of the larger export supply from $B$ to $A$ in our analysis ( $X_{B}$ is located further to the right than $S_{B}$ due to $B$ 's ability to shift its exports from 
$C$ to $A$ ). However, for the same reason, $A$ loses more in this case than in the standard analysis and $B$ gains more.

What about the impact on the PTA as a whole? In the first case where $X_{B}$ intersects $A$ 's demand curve at point $L$, the bloc gains KLV. In the second case where $X_{B}$ intersects $A$ 's demand curve at point $\mathrm{U}$, the bloc gains KUYV from trade creation but loses UYZ from trade diversion. The net impact KUZV is thus likely to be positive (see Figure 1), though if $Z$ is located to the left of $V$, the cost of trade diversion may be larger than the gain from trade creation. ${ }^{6}$ In the third case where the export supply curve $X_{B}$ intersects the horizontal section FK to the left of $\mathrm{K}$, the bloc loses from trade diversion, with $B$ inefficiently expanding output and reducing consumption because of selling in a protected market. If $S_{B}$ is parallel to $X_{B}$, then the bloc loss is the same in both analyses: it is equal to JIG.

In conclusion, the effect on the bloc is negative if post-PTA imports from $B$ are less than $M_{3}$, they are likely to be positive between $M_{3}$ and $M_{4}$, become increasingly positive as imports approach $M_{4}$, and they are equal to KLV at $M_{4}$. Given the possibility of shifting $B$ 's exports from $C$ to $A$, there is a greater likelihood that the equilibrium will not be in the negative zone in our analysis when compared to the standard one. The likelihood of higher imports is further increased in the analysis below when considering indirect trade deflection.

Let us return to the "natural trading partner" hypothesis. Note that the impact of the PTA on A's welfare is ambiguous. It is negative for $X_{B}<M_{3}$, ambiguous for $M_{3}$ $<X_{B}<M_{4}$, and positive for $X_{B}=M_{4}$. Note also that, as (post-PTA) $X_{B}$ increases, the PTAs impact on As welfare worsens for $X_{B}<M_{3}$, and improves for $M_{3}<X_{B}<M_{4}$. However, the "natural trading partner" hypothesis is specified in terms of pre-PTA trade volumes, and we have shown that $B$ 's pre-PTA volume of trade with $A$ is indeterminate. Its volume is thus unrelated to the PTA's impact on A's welfare or on the bloc's welfare.

Our results so far differ in several ways from the traditional analysis. First, we find no relation between initial trade flows (indeterminate) and a PTAs welfare effect, while the standard analysis concludes to a negative relation. ${ }^{7}$ Second, if $X_{B}$

\footnotetext{
${ }^{6}$ If $B$ is able to satisfy $A$ 's pre-PTA import demand $M_{3}$ at price $P_{C}$ (i.e., $Z$ is equal to or to the right of $V$ ), then the bloc gains from the PTA. The likelihood of a net gain is higher as $U$ is closer to $L$, and for a given $U$ it increases as $X_{B}$ is less elastic and $D_{A}$ is more elastic. For instance, assume $K U=U L$. Then, if $X_{B}$ and $D_{A}$ are equally elastic, the export supply curve goes through point $V$, and the net gain equals $K U V$. ${ }^{7}$ The conclusion in some of the standard studies is in terms of post-PTA trade flows, but there is an implicit monotonic relationship between pre- and post-PTA trade volumes; a rightward shift in B's export supply curve in those studies raises both the pre-PTA and post-PTA trade volumes.
} 
$<M_{3}$ in the post-PTA situation, then the losses to $\mathrm{A}$ are larger in our analysis because $X_{B}$ is larger than $S_{B}$ by the amount of pre-PTA exports from $B$ to $C$ which are shifted to $B$ 's market after the formation of the PTA. The losses to the bloc are the same in both analyses (assuming that $\mathrm{S}_{\mathrm{B}}$ is parallel to $X_{B}$ ) and do not vary with the level of post-PTA imports. The likelihood that $B$ is able to satisfy $A$ 's import demand at price $P_{C}$ is greater in our analysis than in the standard one. Thus, the likelihood that $A$ and the bloc will benefit from the PTA is larger as well. And the likelihood is smaller that the export supply curve $X_{B}$ intersects the horizontal section FK to the left of $K$ where the bloc loses. Thus, from the bloc's viewpoint, such a PTA is more likely to be beneficial than in standard analysis. And as examined below in indirect trade deflection further increases the likelihood that the PTA will be beneficial.

Assume now that $B$ is larger than $A$. Then, A's gains are larger. First, $A$ is likely to gain more on its exports to $B$. Being larger, $B$ is likely to continue to import from $C$ after the PTA with $A$ is formed. Since $B$ continues to charge a tariff on imports from $C$, A obtains an improvement in its terms of trade by selling to $B$ at the higher tariff-inclusive price. Second, a larger $B$ is more likely to satisfy $A$ 's import demand at the world price.

\section{$B$ switches from exporter to $\boldsymbol{C}$ to importer from $\boldsymbol{C}$.}

Rules of origin (ROOs) in FTAs are established to prevent "trade deflection," that is, to prevent goods from the rest of the world imported by member countries with the lowest tariff rates from being resold to partner countries with higher tariff rates. Trade deflection would render protection in high-tariff countries ineffective, with the effective tariff equal to the lowest one in the bloc. It would be equivalent to a CU with the CET set equal to the lowest tariff in the union. ${ }^{8}$ ROOs were designed to prevent this. However, Richardson $(1994,1995)$ notes that there is a way around ROOs, a mechanism he termed "indirect trade deflection." This is examined below.

Since $B$ can import the good from $C$, it can sell these imports to its own consumers, and export to $A$ the output that was previously consumed domestically in $B$ (assuming $B$ does consume the good). This only takes place if $B$ 's import tariff is lower than $A$ 's, and not if the PTA formed between $A$ and $B$ is a CU rather than a FTA, nor if the PTA is an FTA and B imposes a tariff equal to or higher than A's tariff T.

\footnotetext{
${ }^{8}$ This outcome is equivalent to a proposal made by Bhagwati to strengthen GATT's Article XXIV. One difference is that high tariff countries lose all tariff revenues under indirect trade deflection.
} 
Figure 2.

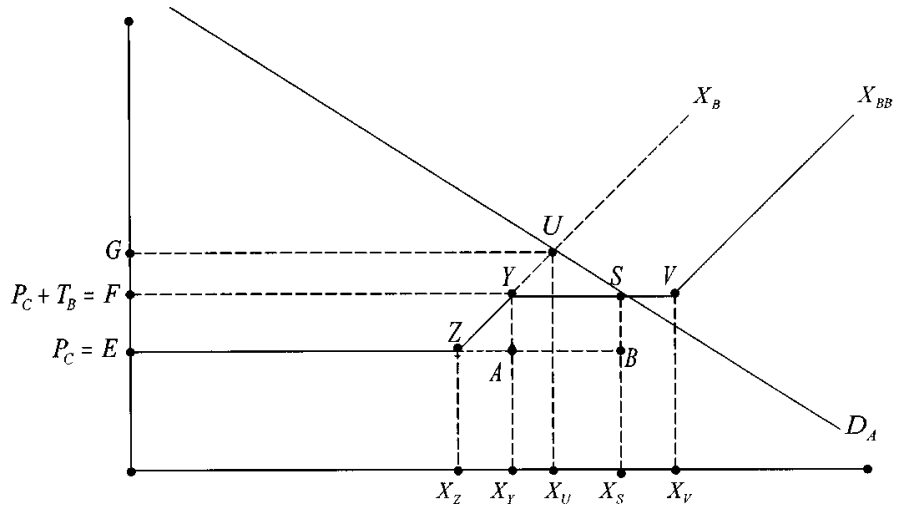

How likely is it for the legal tariff rate to be lower on exports than on imports? The relation between the tariff rate and an index $Z=(X-M) /(X+M)$ was examined for both Argentina and Brazil in 1992 by tariff line. Note that $Z$ increases with $X$ and decreases with $M$, varying from 1 for $M=0$ to -1 for $X=0$. We found a significantly negative correlation between the tariff rate and $Z$ in both countries. Thus, the tariff rate was lower where exports tended to be relatively more important.

Based on these limited findings, the possibility that $T_{B}<T$ (where $T_{B}$ is $B$ 's tariff on its imports of the good) and that $B$ might import the good from $C$ for domestic consumption and increase its exports to $A$ is a realistic possibility. This possibility of arbitrage between producers in $A$ and $B$ once the PTA is formed increases the likelihood that equilibrium will be on the horizontal segment of $B$ 's export supply curve. The height of the horizontal segment depends on the level of tariffs, if any, applied by $B$ on its imports.

How does $B$ 's export supply curve to $A$ look in this case? A's shown in Figure 2 by $X_{B B}$, it has five segments. As examined before, it is equal to zero up to point E, and horizontal at level $P_{C}$ up to point $Z$ where all exports (volume $X_{Z}$ ) forthcoming at that price are sold in $A$ (and none in $C$ ). Beyond point $Z$, a higher price is needed to elicit a larger volume of exports from $B$ to $A$. This is represented by the segment ZY between prices $P_{C}$ and $P_{C}+T_{B}$. At price $P_{C}+T_{B}, B$ will import from $C$ for domestic consumption and sell to $A$ the output that was consumed domestically. This is shown by the segment $Y V$, where $X_{V}$ is $B$ 's total output at price $P_{C}+T_{B}$. Finally, beyond $X_{V}, B$ 's export supply curve is upward sloping again and equals Bs output supply.

What difference does the possibility of indirect trade deflection make in this 
case? It makes no difference if $T_{B}=T$ or if $A$ 's import demand intersects $B$ 's export supply curve at point $Y$ or to its left in Figure $2 .{ }^{9}$ If As demand curve intersects $B$ 's supply curve to the right of point $Y$, then indirect trade deflection makes a difference. For instance, in Figure 2, B's export supply curve in the absence of indirect trade deflection, $X_{B}$, intersects $A$ 's demand curve in point $\mathrm{U}$ which corresponds to point $U$ in Figure 1 while $B$ 's export supply curve in the presence of indirect trade deflection, $X_{B B}$, intersects $A$ 's demand curve in point $S$. Thus, with indirect trade deflection, $A$ gains area USFG. $B$ gains ABSY (the tariff revenues on its additional imports) and loses UYFG. The PTA as a whole gains ABSUY. Thus, indirect trade deflection by the partner country is beneficial for the home country and for the PTA as a whole, though not necessarily for the partner country. Note that if $X_{B B}$ intersects $D_{A}$ between $U$ and $S$, gains are smaller but the qualitative results remain unchanged.

On the other hand, if $X_{B B}$ intersects the horizontal segment FK to the left of $K$ in Figure 1, then $A$ loses more, $B$ gains more, and bloc losses are unchanged (with $X_{B}$ parallel with $X_{B B}$ ). Thus the impact on bloc welfare of forming a bloc is more likely to be positive and less likely to be negative once both export switching and indirect trade deflection are taken into account. Also, the gains are likely to be larger, while the losses are likely to be unchanged.

\section{$B$ Imports from $C$.}

Assume an FTA with $T_{B}<T$. This case is the one typically considered in the regional integration literature with homogeneous goods. ${ }^{10}$ Bhagwati and Panagariya (1996, pp. 48-51) argue that, with indirect trade deflection, $B$ 's export supply curve to $A$ ( $S_{B}$ in Figure 1 ) shifts to the right, coinciding now with $B$ 's output supply curve. This holds for prices higher than $P_{C}+T_{B}$, though not for prices lower than or equal to $P_{C}+T B$.

Let us examine $B$ 's export supply at prices lower than or equal to $P_{C}+T_{B}$. Since $B$ imports from $C, B$ 's producer price is $P_{C}+T_{B}$. On the other hand, the price it can obtain in $A$ before formation of the PTA is $P_{C}$. Hence, no producer in $B$ will sell in $A$ and $B$ sells all its output in its own market. In fact, $B$ 's export supply to $A$ is zero for prices below $P_{C}+T_{B}$ (up to point $\mathrm{F}$ in Figure 2). It is horizontal at the price $P_{C}+T_{B}$ because $B$ can sell its entire output to $A$ and import its consumption needs.

\footnotetext{
${ }^{9}$ Indirect trade deflection may matter even when $T_{B}=T$ if smuggling takes place between A and B. This is examined in Schiff (1997) and is abstracted from here.

${ }^{10}$ See the references at the start of Section 3.
} 
After that point, $B$ 's export supply curve becomes upward sloping and equals its output supply curve. As in the previous case, equilibrium and welfare depend on where $A$ 's import demand curve and $B$ 's export supply curve intersect. However, there is no link between the pre-PTA trade volume and post-PTA welfare since the pre-PTA trade volume between $A$ and $B$ is equal to zero.

The difference with the previous case where $B$ is an exporter of the good is that there is no export switching in this case, and $B$ exports to $A$ only at a price $P_{A}>P_{C}$ $+T_{B}$ rather than at $P_{A}>P_{C}$. There are two possible outcomes. Either the price is unchanged, and is the same whether $B$ is an exporter or an importer of the good (i.e., $P_{A}=P_{C}+T$ ), with $A$ continuing to import from $C$ and with the welfare effect being the same whether $B$ is exporter or importer; or the price in $A$ is lower when $B$ is an exporter, with larger gains from trade creation and smaller losses from trade diversion. Note also that the latter situation is more likely to prevail when $B$ is an exporter rather than an importer. The bloc is thus likely to do better in the case where $B$ is an exporter.

\section{Small (Large) in Partner's (Outside) Market.}

A forms a PTA with $C$. If B exports to $C, B$ 's exports to $A$ are indeterminate before the PTA is formed. Once it is formed, $B$ only sells to $C$ at $P_{C}$ (rather than at $P_{C}-T$ in $A$ ). $B$ and $C$ are unaffected and $A$ gains KLV. If $B$ imports from $C$, it does not sell to $A$ either before or after the PTA. Once again, $B$ and $C$ are unaffected and $A$ gains KLV.

\section{Conclusions and Policy Recommendations}

This paper does not ask whether a country should form or join a trading bloc. ${ }^{11}$ Rather, it asks: If a country has decided to form or join a trading bloc, what partner or partners should it select? As the paper has shown, the pre-PTA volume of trade is not a useful criterion for selecting a partner. The reason is that the pre-PTA volume is equal to zero if the partner is an importer of the good sold to the home country and it is indeterminate if the partner is an exporter of that good.

Thus, one cannot conclusively argue, as done by adherents of the "natural trading partner" hypothesis, that the welfare impact of a PTA is higher if member countries trade disproportionately with each other before the PTA is formed.

\footnotetext{
${ }^{11}$ Neither does it examine the issue of whether a country should liberalize regionally or multilaterally. On the systemic issue of regionalism versus multilateralism, see Winters (1996).
} 
However, neither can one conclusively argue the opposite (as done by opponents of the hypothesis), namely that the welfare impact is worse if member countries already trade disproportionately with each other before the PTA is formed.

Some of the conclusions from our analysis are as follows:

For given tariff rates, the home country is better off if the partner country is large. First, a large partner is more likely to satisfy the home country's import demand at the world price. Second, the home country is likely to gain more on its exports to the partner. The reason is that if the partner is large, it is likely to continue to import from the world market after the PTA is formed. And since the partner charges a tariff on imports from the world market, the home country is more likely to obtain an improvement in its terms of trade by selling to the partner at the higher tariff-inclusive price if the partner is large.

Second, the PTA as a whole is likely to be better off if each country imports what the other exports (rather than each country importing what the other imports). Losses are similar but less likely, while gains are both more likely and the same or larger.

Based on these conclusions, I propose to define countries as being "natural trading partners" if they are characterized by complementarity in trade rather than by substitutability. In other words, countries are defined as "natural trading partners" if they tend to import what the prospective partner exports. Under that definition, the "natural trading partner" hypothesis is likely to hold. ${ }^{12}$

\section{Acknowledgements}

The author would like to thank Alan Winters and participants to the World Bank International Trade Seminar for their comments. This paper represents the authors views and not necessarily those of the World Bank, its member governments or its affiliated institutions.

Date accepted: October, 2000

\footnotetext{
${ }^{12}$ Kowalczyk and Wonnacott (1991) use a somewhat different definition of substitution and complementarity. They define a "substitute ("complement) trading club" as one that leads to reduced (higher) import demand by the club from the rest of the world. The concept is used in the analysis of hubs and spokes in Kowalczyk and Wonnacott (1992) and in the analysis of side-payments to facilitate trade negotiations in Kowalczyk and Sjostrom (1994).
} 


\section{References}

Bagwell, K. and R.W. Staiger (1993a), "Multilateral Tariff Cooperation During the Formation of Regional Free Trade Areas.” NBER Working Paper No. 4364.

Bagwell, K. and R.W. Staiger (1993b), "Multilateral Tariff Cooperation During the Formation of Customs Unions." Northwestern University Center for Mathematical Studies in Economics and Management Science. Discussion Paper 1070.

Bhagwati, J. (1993), "Regionalism and multilateralism: an overview." Chapter 2 in De Melo, J. and A. Panagariya eds. New Dimensions in Regional Integration. Cambridge: Cambridge Univ. Press.

Bhagwati, J. and A. Panagariya (1996), "Preferential Trading Areas and Multilateralism Strangers, Friends or Foes?" in Bhagwati and Panagariya eds. The Economics of Preferential Trade Agreements. Washington, D.C.: AEI Press.

Bond, E.W. and C. Syropoulos (1996), "Trading Blocs and the Sustainability of Interregional Cooperation" in M. Canzoneri, W. Ethier and V. Grilli eds. The New Transatlantic Economy. Cambridge University Press, Cambridge.

Cadot, O., J. de Melo and M. Olarreaga (1996), "Regional Integration and Lobbying for Tariffs against Non-Members." CEPR Discussion Paper 1448. Center for Economic Policy Research, London.

Deardorff, A.V. and R.M. Stern (1994), "Multilateral Trade Negotiations and Preferential Trading Arrangements." Chapter 2 in Deardorff and Stern eds. Analytical and Negotiating Issues in the Global Trading System. Ann Arbor: Univ. of Mich. Press.

EU. 1995. "Free Trade Areas: An Appraisal," Communication from the EU Commission to the EU Council.

Grossman, G. and E. Helpman (1994), "Protection for Sale." American Economic Review 84(4), 833-50.

Grossman, G. and E. Helpman (1995), "The Politics of Free Trade Agreements." American Economic Review 85(4), 667-90.

Kowalczyk, C. and R. Wonnacott (1991), "Substitute and Complement Trading Clubs." Dartmouth College, Department of Economics Working Paper No. 91-16.

Kowalczyk, C. and R. Wonnacott (1992), "Hubs and Spokes and Free Trade in the Americas.” NBER Working Paper No. 4198.

Kowalczyk, C. and T. Sjostrom (1994), "Bringing GATT into the Core." Economica 61, 301-17.

Krugman, P. (1991), "The move to free trade zones," in Symposium on Policy Implications of Trade and Currency Zones, sponsored by the Federal Reserve Bank of Kansas City

Krugman, P. (1993), "Regionalism versus multilateralism: analytical notes." Chapter 3 In De Melo, J. and A. Panagariya eds. New Dimensions in Regional Integration. Cambridge: Cambridge Univ. Press.

Lipsey, R. (1960), “The theory of customs unions: A general survey.” Economic Journal 
$70,498-513$.

Lloyd, P.J. (1982), “3×3 Theory of Customs Unions.” Journal of International Economics 12, 41-63.

Michaely, M. (1998), "Partners to a preferential trade agreement: Implications of variying size." Journal of International Economics 46, 73-85.

Olarreaga, M. and I. Soloaga (1998), "Endogenous Tariff Formation: The Case of Mercosur." World Bank Economic Review 12(2), 297-320.

Panagariya, A. (1996), "The Free Trade Area of the Americas: Good for Latin America?" World Economy 19(5), 485-515.

Panagariya, A. (1997), "Preferential trading and the myth of natural trading partners." Japan and the World Economy 9, 471-89.

Panagariya, A. (1999), "Preferential Trade Liberalization: The Traditional Theory and New Developments," Mimeo, Dept. of Economics, Univ. of Maryland.

Richardson, M. (1994), "Why a Free Trade Area? The Tariff Also Rises." Economics and Politics 6(1), 79-96.

Richardson, M. (1995), "Tariff revenue competition in a free trade area." European Economic Review 39, 1429-37.

Riezman, R. (1979), “A $3 \times 3$ Model of Customs Unions.” Journal of International Economics 9, 341-54.

Schiff, M. (1997), "Small is Beautiful: Preferential Trade Agreements and the Impact of Country Size, Market Share, and Smuggling." Journal of Economic Integration 12(3), 359-87.

Summers, L. (1991), "Regionalism and the world trading system," in Symposium on Policy Implications of Trade and Currency Zones, sponsored by the Federal Reserve Bank of Kansas City

Winters, L.A. (1996), "Regionalism versus Multilateralism.” World Bank Policy Research Working Paper No. 1687. Washington, D.C.

Wonnacott, P. and M. Lutz (1989), "Is There a Case for Free Trade Areas?" in Schott, J.J. ed. Free Trade Areas and U.S. Trade Policy, pp. 59-84. Washinton, D.C.: Inst. Int. Econ.

Wonnacott, P. and R. Wonnacott (1981), "Is Unilateral Tariff Reduction Preferable to a Customs Union? The Curious Case of the Missing Foreign Tariffs." American Economic Review 71(4), 704-14.

World Bank (2000). Trade Blocs. A Policy Research Report. 